\title{
Factors impacting e-learning in health sciences education: a protocol for systematic review and meta-analysis
}

\author{
Krishna Regmi ${ }^{\mathrm{a},} *$ and Linda Jones ${ }^{\mathrm{b}}$ \\ ${ }^{a}$ Faculty of Health and Social Sciences, University of Bedfordshire, Luton, United Kingdom; \\ ${ }^{b}$ Centre for Medical Education, School of Medicine, University of Dundee, United Kingdom
}

\section{*Corresponding author}

Faculty of Health and Social Sciences, Institute for Health Research, University of

Bedfordshire, Luton, LU2 8LE, United Kingdom. Email: Krishna.r.regmi@gmail.com 


\title{
Factors impacting e-learning in health sciences education: a protocol for systematic review and meta-analysis
}

\begin{abstract}
E-learning has been widely used in higher education as it provides better access to learning resources online, utilising technology - regardless of learners' geographical locations and timescale - to enhance learning. Despite growing evidence claiming that e-learning is as effective as traditional means of learning, there is very limited evidence. This protocol aims to assess the effects of e-learning factors that impact on health sciences education (HSE). We will conduct a systematic review meta-analysis research of both randomised controlled trials and non-randomised controlled trials. Seven databases - MEDLINE, EMBASE, Allied \& Complementary Medicine, DH-DATA, PsycINFO, CINAHL, and Global Health - will be searched, from 1980 through 2020. The PRISMA-P checklist will be used while preparing this protocol. Two reviewers will independently screen the papers and extract data. We will utilise the JBI quality appraisal tools for quantitative and qualitative studies, and Mixed Methods Appraisal Tool appraisal tools to assess the quality. A narrative synthesis, using thematic analysis, will be conducted for the included studies. If sufficient data are available, the randomeffects model for meta-analysis will be performed to measure the effect size of elearning on health sciences education or the strengths of relationships. The outcome of this review will provide a useful checklist of potential factors to develop an e-learning approach in HSE. This might provide a basis for developing the best methods of elearning in education so that e-learning policy in education and learning settings in the HSE context could be administered effectively, efficiently and equitably.
\end{abstract}

Keywords: E-Learning; Health Sciences Education; Systematic Review; MetaAnalysis 
medRxiv preprint doi: https://doi.org/10.1101/2020.06.26.20140566; this version posted June 26, 2020. The copyright holder for this preprint (which was not certified by peer review) is the author/funder, who has granted medRxiv a license to display the preprint in perpetuity.

It is made available under a CC-BY-NC-ND 4.0 International license .

\section{Introduction}

There are different meanings or interpretations of e-learning, but employing the technology to provide online access to learning resources for the improvement of learning is the principal aspect of e-learning (Holmes \& Garder, n.d.; Sandars, 2013). E-learning has been defined as an educational method that would facilitate learning by the application of information technology and communication (Golband et al., 2014). Recently, e-learning has been well recognised in medical education and other healthcare disciplines that included the dental, public health, nursing, and other allied healthcare education, which this protocol refers to as health sciences education (HSE). However, the impact of e-learning and its effect on learners' performance or enhancing their learning has been well debated.

Similarly, e-learning has had less impact than intended, and HSE practices have remained largely unchanged over the past decade. Cook et al. (2008) raise some concerns over whether e-learning would actually enhance learning, particularly 'the extent to which knowledgebased learning compared with alternative approaches to medical education'. Though some literatures on e-learning have provided some promises that e-learning would be equally effective as traditional methods of learning or teaching, still there is very limited evidence demonstrating when and how best e-learning enhances education and learning, and the factors associated with it (Childs et al., 2005; Cook et al., 2008; Curran \& Fleet, 2005; Donnelly et al., 2012; McCutcheon et al., 2015; Wutoh et al., 2004). As Kim (2006) argues, most of the published evidences appear to have three major limitations: (a) they are mostly descriptive, (b) they have clearly failed to demonstrate the outcome measures, and (c) the majority have faults due to weakness or inappropriateness in study designs.

Another systematic review, capturing 176 empirical studies, conducted between 1996 and 2008, shows that students in online conditions performed modestly better as compared to those learning the same material through traditional face-to-face instruction (Means et al., 2010). These interpretations, however, should be treated with caution, as the conditions and dimensions for both methods are not the same, particularly the learners' and facilitators' time spent on setting or accomplishing tasks, level of accessibility, and convenience (Cook et al., 2010). A Cochrane Review involving 5679 health professionals, published in 2018 , examining the effects of e-learning versus traditional learning, reported little or no differences in patient outcomes or health professionals' skills and behaviours (Vaona et al., 2018). 
Similarly, several studies make claims for e-learning and learning enhancement, but the results appeared rather mixed (Cappel \& Hayen, 2004; Cook et al., 2008; Ruiz et al., 2006). It has been found that if we simply compare the outcomes between e-learning and no training interventions, e-learning is generally far more effective in gaining knowledge and skills including positive behaviours, but this does not necessarily mean that the results are significant mainly due to the fact that results are heterogeneous (i.e. inconsistent results) and are frequently in small studies (Al-Shorbaji et al., 2015; Fletcher, 2007). Until now there has been limited, scattered and patchy evidence in relation to the effects of e-learning for HSE (Al-Shorbaji et al., 2015; Kim, 2006). Our preliminary scan showed that no earlier systematic review and meta-analysis protocol has addressed the objectives of this systematic review.

\section{Aims and objectives}

The aim of this review protocol is to assess the effects of e-learning factors that impact on health sciences education.

\section{Primary objective:}

The primary objective is to identify, appraise and synthesise the existing evidence on barriers and facilitators to e-learning in HSE.

\section{Secondary objective:}

A secondary objective is to quantify and analyse to measure the effect of e-learning on health sciences education or the strengths of relationships.

To the best of our knowledge, this is the first systematic review and meta-analysis research protocol examining and synthesising the factors - enablers or barriers - evidencing to elearning in making health sciences education effective.

\section{Methods}

\section{Study design}

This study will utilise a systematic review and meta-analysis method, which will consider both randomised controlled trials and non-randomised trials (prospective and retrospective observational studies) of good-quality studies. Chalmers and Atlman (1995) define systematic review as a "review that has been prepared using a systematic approach to minimise biases and random errors which is documented in a materials and methods section." 
Meta-analysis includes the statistical analysis for combining the results of a number of individual studies to produce summary results, e.g. pooled research studies (Khan et al., 2011). The Preferred Reporting Items for Systematic Reviews and Meta-Analysis Protocols (PRISMA-P) checklist has been used in the preparation of this protocol (Shamseer et al., 2015).

\section{Search strategies}

A broad search strategy will be designed to maximise the level of sensitivity to identify potential studies and specificity to identify definitely relevant studies in searching (Higgins et al., 2019), and improve both the recall and precision ratios (Katcher, 2006). A systematic structured literature search of seven databases - MEDLINE, EMBASE, Allied \& Complementary Medicine, DH-DATA, PsycINFO, CINAHL, and Global Health - will be conducted, from 1980 through 2020. Primary search terms are e-learning (all synonyms) and health sciences education (all synonyms) using 'Textword searching' - searching for a word or phrase appearing anywhere in the document, where the document is the citation (article title, journal name, author), not the full text of an article, and 'Thesaurus (MeSH, EMTREE) searching', employing Boolean operators and truncations (Table 1).

The search structure will consist of the following:

1. Break down the search into separate concepts.

2. Search each concept separately using free and MeSH terms to obtain four sets of results.

3. Combine the four sets so that both concepts will be in the same references.

4. Consider using relevant limits (e.g. English, humans, age groups). 
medRxiv preprint doi: https://doi.org/10.1101/2020.06.26.20140566; this version posted June 26, 2020. The copyright holder for this preprint (which was not certified by peer review) is the author/funder, who has granted medRxiv a license to display the preprint in perpetuity.

It is made available under a CC-BY-NC-ND 4.0 International license .

Table 1. Search strategy for the MEDLINE

\begin{tabular}{|c|c|c|}
\hline Study aim & \multicolumn{2}{|c|}{$\begin{array}{l}\text { The aim of this review protocol is to assess the effects of e-learning factors } \\
\text { that impact on health sciences education }\end{array}$} \\
\hline Question part & Question term & Synonyms \\
\hline - Population/setting & $\begin{array}{l}\text { Adult, human } \\
\text { (professionals, practitioners, } \\
\text { postgraduate and undergraduate } \\
\text { students) }\end{array}$ & \\
\hline \multirow[t]{20}{*}{ - Study factor } & \#1. e-learning & \#2. online learning \\
\hline & & \#3. education, distance \\
\hline & & \#4. online instruction \\
\hline & & \#5. distance learning \\
\hline & & \#6. blended learning \\
\hline & & \#7. Computer based learning \\
\hline & & \#8. electronic education \\
\hline & & \#9. virtual learning \\
\hline & & \#10. Technology enhanced learning \\
\hline & \#11. health sciences education & \#12. health sciences. \\
\hline & & \#13. medical education \\
\hline & & \#14. continuing medical education \\
\hline & & \#15. Basic Sciences \\
\hline & & \#16. public health education \\
\hline & & \#17. nursing education \\
\hline & & \#18. allied health education \\
\hline & & \#19. general practice \\
\hline & & \#20. public health nursing \\
\hline & & \#21. primary health care \\
\hline & & \#22. general practice \\
\hline \multirow[t]{5}{*}{ - Ideal design } & 23. Methodological terms & \#24. clinical trials \\
\hline & & \#25. cross-sectional studies \\
\hline & & \#26. Survey \\
\hline & & \#27. qualitative research \\
\hline & & \#28. quantitative research \\
\hline \multirow[t]{8}{*}{ - Outcome } & \#29. Impact & \#30. effective \\
\hline & & \#31. improving \\
\hline & & \#32. performance \\
\hline & & \#33. enhancing \\
\hline & & \#34. barriers \\
\hline & & \#35. challenges \\
\hline & & \#36. facilitators \\
\hline & & \#37. drivers \\
\hline
\end{tabular}

Thus, a search string would be: (\#1 OR \#2 OR \#3 OR \#4 OR\#5 OR \#6 OR \#7 OR \#8 OR\#9 OR \#10) AND (\#11 OR \#12 OR \#13 OR \#14 OR \#15 OR\#16 OR \#17 OR \#18 OR \#19 OR\#20 OR \#21 OR\#22) AND (\#24 OR \#25 OR \#26 OR \#27 OR \#28) AND (\#29 OR \#30 OR \#31 OR \#32 OR\#33 OR \#34 OR\#35 OR \#36 OR\#37)

Note: Search terms will be modified as needed for use in other databases

The 'Related Articles' feature in PubMed will be consulted. Searches will also be supplemented by reviewing the reference lists ('references of references') of selected articles to find any other relevant papers. We will also ask subject experts/information specialists 
from both Universities (Bedfordshire and Dundee) to verify the research strategy, ensuring its comprehensiveness.

\section{Inclusion and exclusion criteria}

It has been argued that inclusion and exclusion criteria for any research should be set up in line with the proposed aim and objectives, ensuring that peer-review articles will not only be drawn within the context and boundaries of the research objectives, but also will be structured in a way that would enable the researcher to answer the proposed study objectives (Centre for Reviews and Dissemination, 2008). The inclusion and exclusion criteria for this study have been provided.

\section{Criteria for considering studies for review}

\section{Inclusion criteria}

- Type of studies: Any primary study designs, both randomised controlled trials and non-randomised trials (prospective and retrospective observational studies) that reported or identified or quantified barriers and facilitators to e-learning will be eligible.

- Journal quality: Articles published in peer-reviewed journals.

- Articles discussing factors - barriers or facilitators - about el-HSE as outcome measures.

- Language and time limit: Articles published in English language and published after 1980.

\section{Exclusion criteria}

- Articles published in secondary, non-empirical studies or grey literature.

- Commentaries, review documents, case studies, letters, discussion papers, posters, conference abstracts, congress reports and dissertations.

- Articles not published in peer-reviewed journals.

- Articles falling outside el-HSE.

- No full text available.

- Articles not published in English language and published before 1980. 
medRxiv preprint doi: https://doi.org/10.1101/2020.06.26.20140566; this version posted June 26, 2020. The copyright holder for this preprint (which was not certified by peer review) is the author/funder, who has granted medRxiv a license to display the preprint in perpetuity.

It is made available under a CC-BY-NC-ND 4.0 International license .

\section{Participants}

Enablers or barriers related to e-learning would vary across different institutions and stakeholders. In order to capture the broad-spectrum eligible population, we will consider professionals, practitioners, postgraduate and undergraduate students as well as policyplanners, policy-makers or researchers, and administrators including continuing professional development for healthcare professionals within the fields of medical, dental, public health, nursing, and other allied healthcare educations.

\section{Interventions}

Any interventions i.e. computer technologies used to facilitate the provision of online access to learning resources for the improvement of learning would be considered, e.g. e-learning, online learning, online instruction, distance learning, distance teaching or computer-assisted instruction.

\section{Control/comparators}

Studies will be included regardless of control/comparator group.

\section{Study outcomes}

For the purpose of this study, any type of barriers or enablers to e-learning, primarily in making learning effective, improving learning performance, or enhancing learners' level of knowledge, skills and attitudes would be considered as outcomes. The conceptual meaning of barriers and facilitators has been borrowed from Reynders et al. (2016), i.e. barriers refer to any variable that impedes or obstructs, whereas facilitators would act other way round, e.g. variables that would ease and/or promote the use of e-learning in HSE.

\section{Measure of effect}

For dichotomous data, we will measure the risk ratios (RR). Mean differences, and where appropriate, standardised mean differences will be used for continuous data.

\section{Screening and data extraction}

The literature which will emerge from the databases, snowballing and hand-searching, will be screened at two stages: first, a review of abstracts and titles of the retrieved literature to see whether they will meet minimum inclusion criteria, i.e. whether the paper will address elHSE as this review defines it, and whether the paper will report data on factors - enablers and 
challenges related to learning performance or outcomes, and articles will be removed which do not meet a minimum criterion at this stage. Screening of titles and abstracts will be done with two reviewers. Second, the full text of the included articles will be reviewed using the JBI Critical Appraisal Checklists for qualitative, quantitative studies (Lockwood et al., 2015; Munn et al., 2015) and Mixed Methods Appraisal Tool (MMAT) for mixed-method studies (Hong et al., 2018). At this stage, more articles might be excluded. As Means et al. (2010) argue, the intent of the two-stage approach is to gain efficiency without risking exclusion of potentially relevant, high-quality studies of online learning effects. The standard PRISMA flow diagram (Fig. 1) will be used to provide the process of study selection (Moher et al., 2009).

Figure 1. PRISMA flow diagram
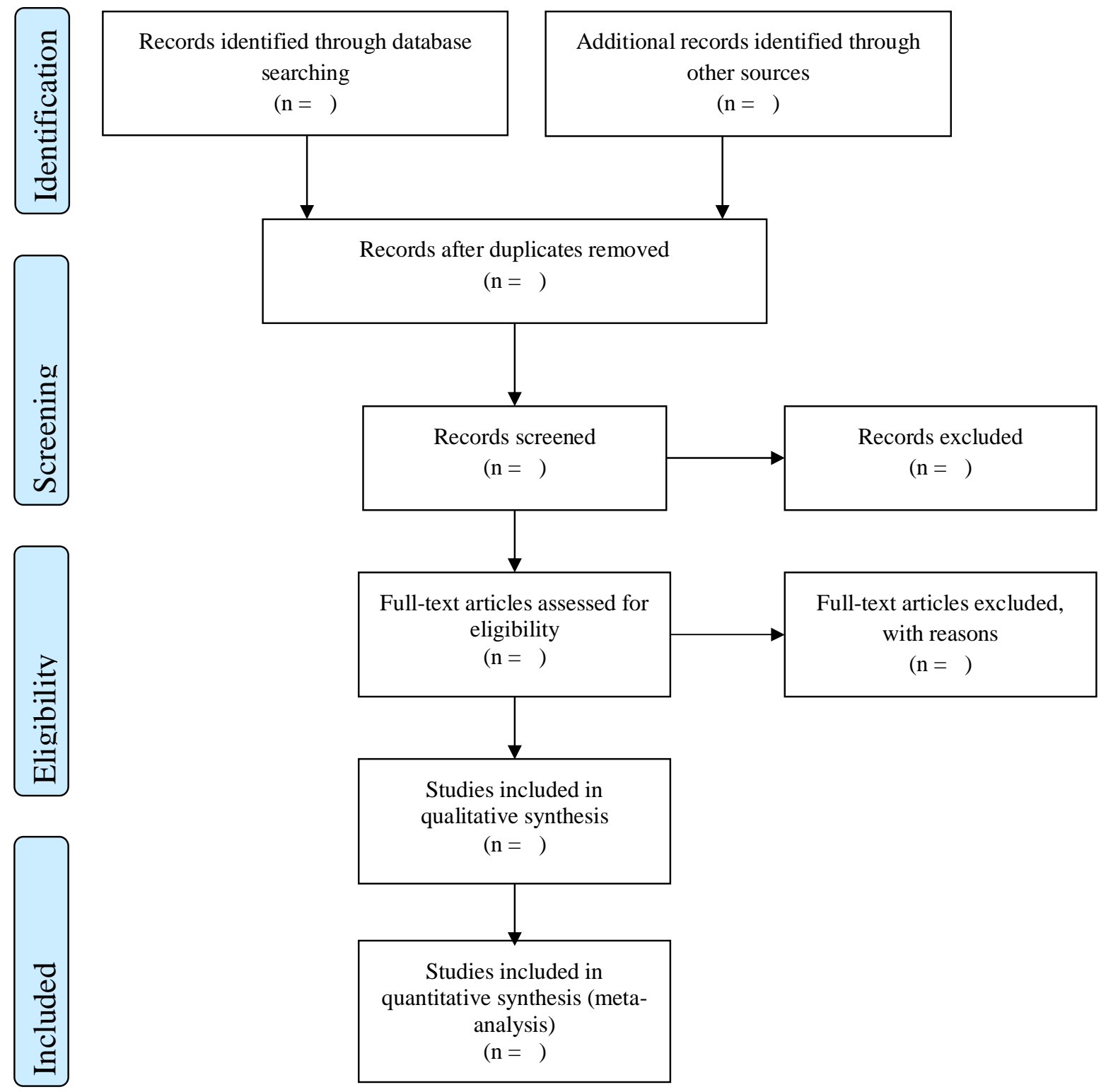
medRxiv preprint doi: https://doi.org/10.1101/2020.06.26.20140566; this version posted June 26, 2020. The copyright holder for this preprint (which was not certified by peer review) is the author/funder, who has granted medRxiv a license to display the preprint in perpetuity.

It is made available under a CC-BY-NC-ND 4.0 International license .

\section{Quality assessment and risk of bias}

We will utilise the quality assessments using critical appraisal tools (Lockwood et al., 2015;

Munn et al., 2015; Hong et al., 2018) to assess the methodological qualities including the possibility of bias in study design, conduct and analysis. The results of these appraisals will be used to inform the synthesis and interpretation of the study results. Both JBI tools and MMAT have established content validity and have been piloted across all methodologies (Kerins et al., 2018; Pluye, 2015; Souto et al., 2015). The retrieved papers will be assessed by two reviewers (KR and LJ) using the standardized 10-item, 9-item and 5-item critical appraisal checklists for qualitative assessment, quantitative and mixed methods studies, respectively (Table 2 ).

Table 2. Results from the critical appraisal of methodological quality

\begin{tabular}{|c|c|c|c|c|c|c|c|c|c|c|}
\hline \multicolumn{11}{|c|}{$\begin{array}{l}\text { Results from critical appraisal of qualitative studies - JBI Critical Appraisal Checklist for Qualitative } \\
\text { Research (Lockwood et al., 2015) }\end{array}$} \\
\hline $\begin{array}{l}\text { Studies } \\
\text { no/Question } \\
\text { no }\end{array}$ & 1 & 2 & 3 & 4 & 5 & 6 & 7 & 8 & 9 & 10 \\
\hline & & & & & & & & & & \\
\hline & & & & & & & & & & \\
\hline & & & & & & & & & & \\
\hline & & & & & & & & & & \\
\hline In total & & & & & & & & & & \\
\hline \multicolumn{11}{|c|}{$\begin{array}{l}\text { Results from critical appraisal of quantitative study - JBI Critical Appraisal Checklist for Quantitative } \\
\text { Research or Prevalence Data (Munn et al., 2015) }\end{array}$} \\
\hline $\begin{array}{l}\text { Study } \\
\text { no/question } \\
\text { no }\end{array}$ & 1 & 2 & 3 & 4 & 5 & 6 & 7 & 8 & 9 & \\
\hline & & & & & & & & & & \\
\hline In total & & & & & & & & & & \\
\hline \multicolumn{11}{|c|}{ Results from critical appraisal of mixed methods study - Mixed Methods Appraisal Tool (Hong et al., 2018) } \\
\hline \multicolumn{11}{|c|}{\begin{tabular}{l|l|l|l|l|l|l|l|l|l|}
$\begin{array}{l}\text { Study } \\
\text { no/question } \\
\text { no }\end{array}$ & & & & & & & & & \\
\end{tabular}} \\
\hline $\begin{array}{l}\text { Qualitative } \\
\text { components }\end{array}$ & 1.1 & 1.2 & 1.3 & 1.4 & 1.5 & & & & & \\
\hline $\begin{array}{l}\text { Quantitative } \\
\text { components }\end{array}$ & 4.1 & 4.2 & 4.3 & 4.4 & 4.5 & & & & & \\
\hline & & & & & & & & & & \\
\hline $\begin{array}{l}\text { Mixed } \\
\text { methods }\end{array}$ & 5.1 & 5.2 & 5.3 & 5.4 & 5.5 & & & & & \\
\hline In total & & & & & & & & & & \\
\hline
\end{tabular}

To facilitate comparison of appraisal processes, both reviewers will record the rationale for inclusion or exclusion, and discrepancies will be discussed and resolved by consensus and, in the event a consensus cannot be reached, a third reviewer will arbitrate. 
medRxiv preprint doi: https://doi.org/10.1101/2020.06.26.20140566; this version posted June 26, 2020. The copyright holder for this preprint (which was not certified by peer review) is the author/funder, who has granted medRxiv a license to display the preprint in perpetuity.

It is made available under a CC-BY-NC-ND 4.0 International license .

\section{Assessment of reporting biases}

Publication bias, often called reporting bias and dissemination bias, refers to the concern that studies which report relatively large effects are more likely to be published as compared to studies reporting smaller effects (Borenstein, 2019, p.155). Similarly, published studies that include multiple outcomes would be more likely to report the outcomes than if they showed statistically significant results (Sterne et al., 2008). One approach to address the publication bias is to follow the Trim and Fill procedures, i.e. assessing asymmetry or symmetry in the Funnel plot if more than 10 eligible studies are identified. This approach would estimate the extent of bias or estimate of the adjusted effect size (Duval \& Tweedie, 2000). We will use this approach while assessing the publication bias in the included studies, but Borenstein (2019, p.165) warns that the presence of bias will not automatically invalidate the results.

\section{Data analysis and synthesis}

A narrative synthesis, using thematic analysis, will be conducted for the included studies. Both qualitative and quantitative approaches will be used for data analysis. We will also provide a descriptive numerical summary. Based on the nature of the proposed study topic, we anticipate that included studies would be heterogeneous which preclude meta-analysis.

If sufficient data are available, i.e. identical on important factors and addressing the same fundamental question, to make an inference to a universe of comparable studies, the randomeffects model for meta-analysis will be employed for the analysis to measure the effect size of e-learning on health sciences education or the strengths of relationships using the software Comprehensive Meta-Analysis (CMA, version 3. https://www.metaanalysis.com/pages/new_v3.php?cart=BT2P4569026). The purpose of using a random-effects model in the analysis is "to incorporate the assumption that the different studies are estimating different, yet related, intervention effects" (Higgins et al., 2019). To assess the heterogeneity of effects, $\mathrm{I}^{2}$ together with the observed effects (Q-value, with degrees of freedom) will be used to provide the true effects in the analysis. Q-value is the sum of the squared deviations of all effect sizes from the mean effect size. Generally, this value is on a standardised scale, so that a large deviation gets more weight if the estimate is precise, and less weight if the estimate is imprecise (Borenstein et al., 2009). In fact, $\mathrm{I}^{2}$ statistics does not tell us how much heterogeneity there is, but it tells what proportion of the observed variance reflects in true effect sizes rather than the sampling error. As such, it provides some context for understanding the forest plot (Borenstein et al., 2017). If $\mathrm{I}^{2}$ statistics is low (near zero), 
then most of the variable in the forest plot is due to sampling error. Conversely, if $\mathrm{I}^{2}$ statistics is very high (say, more than $75 \%$ ) then most of the variance in the forest plot is due to variance in true effects. If we could somehow plot the variance of true effects, most of the variance would remain (Higgins et al., 2019).

\section{Tabulating the included studies}

Data from eligible studies will be extracted independently by two reviewers based on the guidelines produced by the Cochrane Group (https://ph.cochrane.org/review-authors) (Table

3). As Rodgers and colleagues confirm, this would not only improve the process of transparency by better understanding what sorts of data extracted from which studies, but also recognising the contribution made by each study to the overall synthesis (Rodgers et al., 2009). In addition, such tables will demonstrate how the individual study area contributes to the reviewers' final conclusion.

Table 3. Data Extraction Template

\begin{tabular}{|c|c|c|}
\hline \multicolumn{3}{|l|}{ Review title/ID: } \\
\hline \multicolumn{3}{|l|}{ Author(s): } \\
\hline \multicolumn{3}{|l|}{ Publication date: } \\
\hline \multicolumn{3}{|c|}{ Date extraction completed: } \\
\hline \multicolumn{3}{|c|}{ Data extractor: } \\
\hline \multicolumn{3}{|l|}{ Publication type } \\
\hline \multicolumn{3}{|l|}{ Citation: } \\
\hline \multicolumn{3}{|l|}{ Notes } \\
\hline \multicolumn{3}{|l|}{ Methods } \\
\hline & Descriptions as stated in the report/paper & $\begin{array}{l}\text { Location (Page/ Para/ Figure } \\
\#)\end{array}$ \\
\hline \multicolumn{3}{|l|}{$\begin{array}{l}\text { Aim and purpose of } \\
\text { study }\end{array}$} \\
\hline \multicolumn{3}{|l|}{$\begin{array}{l}\text { Theoretical } \\
\text { framework/approach }\end{array}$} \\
\hline \multicolumn{3}{|l|}{ Research design } \\
\hline \multicolumn{3}{|l|}{$\begin{array}{l}\text { Method/s of } \\
\text { recruitment of } \\
\text { participants }\end{array}$} \\
\hline \multicolumn{3}{|l|}{ - Sample } \\
\hline \multicolumn{3}{|l|}{$\begin{array}{l}\text { Data collection and } \\
\text { analysis }\end{array}$} \\
\hline \multicolumn{3}{|l|}{$\begin{array}{ll}\text { - } & \text { Methods and } \\
\text { procedures }\end{array}$} \\
\hline \multicolumn{3}{|l|}{$\begin{array}{l}\text { - } \begin{array}{l}\text { Variable of } \\
\text { interest }\end{array} \\
\end{array}$} \\
\hline \multicolumn{3}{|l|}{ Key findings } \\
\hline $\begin{array}{l}\text { Ethical approval } \\
\text { needed/obtained for }\end{array}$ & & \\
\hline
\end{tabular}




\begin{tabular}{|l|l|l|}
\hline study & & \\
\hline $\begin{array}{l}\text { Research strengths } \\
\text { from the literature }\end{array}$ & & \\
\hline $\begin{array}{l}\text { Research gaps from the } \\
\text { literature }\end{array}$ & \\
\hline & & \\
\hline
\end{tabular}

\section{Dealing with missing data}

In the case of missing data that might be important to summarise/synthesise the findings of the study or details of the studies are unclear, corresponding authors of included studies will be contacted.

\section{Sub-group analysis}

We will group by the types of e-learning (e.g. enhanced or adjunct learning - face-to-face learning, blended e-learning model - face-to-face and online learning, and pure online or fully-online learning), by respondents (e.g. medical, nursing and allied healthcare professionals or practitioners), by student (post-graduate and undergraduate).

\section{Risk of bias assessment}

Risk of bias will be examined, as it provides the variation, e.g. heterogeneity in the results of the studies included in the study. As Higgins et al. (2019) argue, rigorously conducted studies in the systematic review would provide more truthful results, and the results from the studies of variable validity would give either false negative or false positive conclusions. Therefore, assessing the risk of bias in all studies in any review is important. In assessing risk, we will create a table with a row for every relevant type of potential bias, and then classify each study on each row as having a low, unclear, or high risk of bias. In this study, the issue of bias will be kept separate from the core analysis - meaning analysis will be performed without worrying about the quality/bias. We will then use the risk of bias table to provide the context for the analysis (Borenstein, 2019). As Borenstein (2019) suggests, "if the analysis shows a clinically and/or substantially important effect, we will assess the entirety of the evidence by considering the risk of bias as well" (p.326). Generally, the bias table provides the type of bias (e.g., selective reporting of outcomes, random sequence generation, allocation of concealment, blinding of participants, personnel and assessors, incomplete outcome data and other potential threats to validity) in each study. If, for example, most rows are unshaded then that it is considered a low risk of bias, whereas if some (or all) rows are either partly shaded or dark (risk of bias will be either unclear or high), this would provide relatively less 
medRxiv preprint doi: https://doi.org/10.1101/2020.06.26.20140566; this version posted June 26, 2020. The copyright holder for this preprint (which was not certified by peer review) is the author/funder, who has granted medRxiv a license to display the preprint in perpetuity.

It is made available under a CC-BY-NC-ND 4.0 International license .

confidence in the results (Higgins et al., 2019). Generally, risk of bias assessment tool will depend on the study type. We will use RoB 2 tool (Sterne et al., 2019) for randomised and ROBINS-I tool (Sterne et al., 2016) for non-randomised trials while assessing the risk of bias.

\section{Ethics}

As this is a protocol for a systematic review and meta-analysis, neither patients nor public participation will be directly involved, and ethics approval and consent will not be required either.

\section{Dissemination}

We will be able to disseminate the study findings using the following strategies: first, a copy of the final systematic review and meta-analysis protocol will be made available at the libraries of both authors' universities (Dundee and Bedfordshire), so that students and staff will be able to gain benefits, largely on how to write a systematic review protocol. Second, we will be published in an academic peer-reviewed journal. Third, an abstract will be presented at suitable national/international medical education or e-learning conferences or workshops.

\section{Discussion}

To the best of our knowledge, this will be the first systematic review and meta-analysis protocol to identify and quantify the potential factors (barriers and facilitators), and analyse to measure the effect size of e-learning on health sciences education or the strengths of relationships. Some evidence suggests that e-learning facilitates the process of learning and thereby changes in practice by supporting instructional design and delivery mechanisms, which captures the developing of materials using set learning objectives, including teaching strategies - embedding feedback and evaluation to influence learners' intrinsic and extrinsic motivation factors. However, how these factors, in fact, would influence examining and synthesising internal, external and contextual factors has not been well researched in the past (Lewis et al., 2014). Second, there are some frameworks and models of online education which employ different methods and tools to collect or gather data, and they mostly used preand post-test questionnaires or self-assessment checklists (Kirkpatrick, 1998; Levy, 2006;

Phillips, 2000; Stufflebeam, 2001). Similarly, another model was more focused on motivating learners and e-moderators in general education, but none of them is specifically designed or developed in line with medical or health sciences education (HSE) (Mayes, 2004). 
These descriptions have illustrated two points: first, a lot of health sciences (or professional) education e-learning research and evaluation clearly lacks some theoretical perspectives. Second, most of the conceptual and theoretical work is based on neither medical nor health sciences education, but several pieces of work look at education generally.

The potential limitations of this study would be that if the retrieved studies would be heterogeneous in nature, we might not be able to perform a meta-analysis measuring the effect size of e-learning on health sciences education or the strengths of relationships. Second, there will be a small number of suitable articles to identify, appraise and synthesise the existing evidence on barriers and facilitators related to e-learning with different disciplines, i.e. nursing, physiotherapy, public health, allied healthcare sciences, etc. Third, this research is unfunded, and both time and resource might be limited. Therefore, articles published in English only will be included in this study.

In light of the identified limitations or challenges, one of the major strengths of this study is to apply transparent methods and approaches for systematic review and meta-analysis so that future researchers, practitioners and academics will be able to reproduce its methodology easily. Similarly, the outcome of this review will provide a useful checklist of potential factors to develop an e-learning approach in HSE. This might provide a basis for developing the best methods of e-learning in education so that e-learning policy in education and learning settings in the HSE context could be administered effectively, efficiently and equitably.

\section{Acknowledgements}

This research protocol is based on ongoing research studies undertaken for medical education by KR at the University of Dundee, UK. The qualitative component of the study is published elsewhere (Regmi \& Jones, 2020).

\section{Disclosure statement}

The authors declare that they have no competing interests.

\section{Funding}


medRxiv preprint doi: https://doi.org/10.1101/2020.06.26.20140566; this version posted June 26, 2020. The copyright holder for this preprint (which was not certified by peer review) is the author/funder, who has granted medRxiv a license to display the preprint in perpetuity.

It is made available under a CC-BY-NC-ND 4.0 International license .

This research received no specific grant from any funding agency in the public, commercial or not-for-profit sectors.

\section{References}

Al-Shorbaji, N., Atun, R., \& Car, J. et al. (2015). E-learning for undergraduate health professional education: a systematic review information of health workforce development. Imperial College/WHO.

Borenstein, M. (2019). Common mistakes in meta-analysis and how to avoid them. USA: Biostat, Inc.

Borenstein, M., Hedges, L, \& Higgins, J, et al. (2009). Introduction to meta-analysis. Wiley.

Borenstein M, Higgins, J., Hedges, L., \& Rothstein, H. (2017). Basics of meta-analysis: I 2 is not an absolute measure of heterogeneity. Research Synthesis Methods, 8(1), 5-18. https://doi.org/10.1002/jrsm.1230

Cappel, J.J., \& Hayen, R. (2004). Evaluating E-Learning: A Case Study. Journal of Computer Information Systems, 44(4), 49-56.

Centre for Reviews and Dissemination. (2008). Centre for Reviews and Dissemination. Systematic Reviews: CRD's guidance for undertaking reviews in health care. Centre for Reviews and Dissemination, University of York.

Chalmers, I., \& Atlman, D. (1995). Systematic reviews. London: BMJ Publishing Group.

Childs, S., Blenkinsopp, E., Hall, A, \& Walton, G. (2005). Effective e-learning for health professionals and students-barriers and their solutions. A systematic review of the literature-findings from the HeXL project. Health Information and Libraries Journal, 22(s2), 20-32. https://doi.org/10.1111/j.1470-3327.2005.00614.x

Cook, D., Levinson, A., Garside, S., Dupras, D., Erwin, P., \& Montori, V. (2008). InternetBased Learning in the Health Professions. JAMA - Journal of the American Medical Association, 300(10), 1181. https://doi.org/10.1001/jama.300.10.1181

Cook, D., Levinson, A., Garside, S., Dupras, D., Erwin, P., \& Montori, V. (2010). Instructional Design Variations in Internet-Based Learning for Health Professions Education: A Systematic Review and Meta-Analysis. Academic Medicine, 85(5), 909922. https://doi.org/10.1097/ACM.0b013e3181d6c319

Curran, V., \& Fleet, L. (2005). A review of evaluation outcomes of web-based continuing medical education. Medical Education, 39(6), 561-567. https://doi.org/10.1111/j.13652929.2005.02173.x

Donnelly, P., Benson, J., \& Kirk, P. (2012). How to succeed at e-learning. BMJ/Wiley- 
medRxiv preprint doi: https://doi.org/10.1101/2020.06.26.20140566; this version posted June 26, 2020. The copyright holder for this preprint (which was not certified by peer review) is the author/funder, who has granted medRxiv a license to display the preprint in perpetuity.

It is made available under a CC-BY-NC-ND 4.0 International license .

Blackwell.

Duval, S., \& Tweedie, R. (2000). Trim and Fill: A Simple Funnel-Plot-Based Method of Testing and Adjusting for Publication Bias in Meta-Analysis. Biometrics, 56(2), 455463. https://doi.org/10.1111/j.0006-341X.2000.00455.x

Fletcher, J. (2007). What is heterogeneity and is it important? British Medical Journal, 334(7584), 94-96. https://doi.org/10.1136/bmj.39057.406644.68

Golband, F., Hosseini, A., \& Mojtahedzadeh, R, et al. (2014). The correlation between effective factors of e-learning and demographic variables in a post-graduate program of virtual medical education in Tehran University of medical sciences. Acta Med Iran, 52, $860-864$.

Higgins, J., Thomas, J., Chandler, J., Cumpston, M., Li, T., Page, M., \& Welch, V. (2019). Cochrane Handbook for Systematic Reviews of Interventions. Wiley .

Holmes B, \& Garder J. (n.d.). E-learning: concepts and practice. Sage.

Hong, Q.N., Pluye, P., \& Fàbregues, S., et al. (2018). Mixed Methods Appraisal Tool (MMAT), version 2018. Registration of Copyright (\#1148552). Canadian Intellectual Property Office.

Katcher, B. (2006). Medline: a guide to effective searching in PubMED \& other interfaces. The Ashbury Press.

Kerins, C., McSharry, J., Hayes, C., Perry, I., Geaney, F., \& Kelly, C. (2018). Barriers and facilitators to implementation of menu labelling interventions to support healthy food choices: a mixed methods systematic review protocol. Systematic Reviews, 7(1), 88. https://doi.org/10.1186/s13643-018-0752-3

Khan, K., Kunz, R., Kleijnen, J., \& Antes, G. (2011). Systematic review: to support evidence based medicine. CRC Press.

Kim, S. (2006). The Future of e-Learning in Medical Education: Current Trend and Future Opportunity. Journal of Educational Evaluation for Health Professions, 3, 3. https://doi.org/10.3352/jeehp.2006.3.3

Kirkpatrick, D. (1998). Evaluating training programs. Berrett-Koehler.

Levy, Y. (2006). Assessing the value of e-learning systems. Information Science Publishing. Lewis, K., Cidon, M., Seto, T., Chen, H., \& Mahan, J. (2014). Leveraging e-Learning in Medical Education. Current Problems in Pediatric and Adolescent Health Care, 44(6), 150-163. https://doi.org/10.1016/j.cppeds.2014.01.004

Lockwood, C., Munn, Z., \& Porritt, K. (2015). Qualitative research synthesis. International Journal of Evidence-Based Healthcare, 13(3), 179-187. 
medRxiv preprint doi: https://doi.org/10.1101/2020.06.26.20140566; this version posted June 26, 2020. The copyright holder for this preprint (which was not certified by peer review) is the author/funder, who has granted medRxiv a license to display the preprint in perpetuity.

It is made available under a CC-BY-NC-ND 4.0 International license .

https://doi.org/10.1097/XEB.0000000000000062

Lockwood, C., Munn, Z., \& Porritt, K. (2015). Qualitative research synthesis: methodological guidance for systematic reviewers utilizing meta-aggregation. International Journal of Evidence-Based Healthcare, 13(3), 179-187.

Mayes, T. \& De Freitas, S. (2004). Review of e-learning theories, frameworks, models. JISC e- learning models desk study. JISC.

McCutcheon, K., Lohan, M., Traynor, M., \& Martin, D. (2015). A systematic review evaluating the impact of online or blended learning vs. face-to-face learning of clinical skills in undergraduate nurse education. Journal of Advanced Nursing, 71(2), 255-270. https://doi.org/10.1111/jan.12509

Means, B., Toyama, Y., \& Murphy, R., et al. (2010). Evaluating of evidence-based practices in online learning: a meta-analysis and review of online learning studies. Centre for Technology in Learning, Department of Education.

Moher, D., Liberati, A., Tetzlaff, J., \& Altman, D. G. (2009). Preferred reporting items for systematic reviews and meta-analyses: The PRISMA statement. BMJ (Online), 339(7716), 332-336. https://doi.org/10.1136/bmj.b2535

Munn, Z., Moola, S., Lisy, K., Riitano, D., \& Tufanaru, C. (2015). Methodological guidance for systematic reviews of observational epidemiological studies reporting prevalence and cumulative incidence data. International Journal of Evidence-Based Healthcare, 13(3), 147-153. https://doi.org/10.1097/XEB.0000000000000054

Phillips, J. (2000). Return on investment in training and performance improvement programs. . Butterworth-Heinemann.

Pluye, P. (2015). Mixed kinds of evidence: synthesis designs and critical appraisal for systematic mixed studies reviews including qualitative, quantitative and mixed methods studies. Evidence Based Medicine, 20(2), 79-79. https://doi.org/10.1136/ebmed-2014110158

Regmi, K., \& Jones, L. (2020). A systematic review of the factors - enablers and barriers affecting e-learning in health sciences education. BMC Medical Education, 20(1), 91. https://doi.org/10.1186/s12909-020-02007-6

Reynders, M., Laura R, Luisa L, Nicola D, Jan D, Nia R, \& Sharon M. (2016). Barriers and facilitators to the implementation of orthodontic mini-implants in clinical practice: a protocol for a systematic review and meta-analysis. Systematic Reviews, 5(1), 22. https://doi.org/10.1186/s13643-016-0198-4

Rodgers, M., Sowden, A., Petticrew, M., Arai, L., Roberts, H., Britten, N., \& Popay, J. 
medRxiv preprint doi: https://doi.org/10.1101/2020.06.26.20140566; this version posted June 26, 2020. The copyright holder for this preprint (which was not certified by peer review) is the author/funder, who has granted medRxiv a license to display the preprint in perpetuity.

It is made available under a CC-BY-NC-ND 4.0 International license .

(2009). Testing Methodological Guidance on the Conduct of Narrative Synthesis in Systematic Reviews. Evaluation, 15(1), 49-73.

https://doi.org/10.1177/1356389008097871

Ruiz, J., Mintzer, M., \& Leipzig, R. (2006). The Impact of E-Learning in Medical Education. Academic Medicine, 81(3), 207-212. https://doi.org/10.1097/00001888-20060300000002

Sandars, J. (2013). E-learning. Oxford textbook of medical education (Walsh A (ed.)). Oxford University Press.

Shamseer, L., Moher, D., Clarke, M., Ghersi, D., Liberati, A., Petticrew, M., Shekelle, P., \& Stewart, L. A. (2015). Preferred reporting items for systematic review and meta-analysis protocols (PRISMA-P) 2015: elaboration and explanation. British Medical Journal, 349(jan02 1), g7647-g7647. https://doi.org/10.1136/bmj.g7647

Souto, R., Khanassov, V., Hong, Q., Bush, P., Vedel, I., \& Pluye, P. (2015). Systematic mixed studies reviews: Updating results on the reliability and efficiency of the mixed methods appraisal tool. International Journal of Nursing Studies, 52(1), 500-501. https://doi.org/10.1016/j.ijnurstu.2014.08.010

Sterne, J., Hernán, M., Reeves, B., Savović, J., Berkman, N., Viswanathan, M., Henry, D., \& Altman, D. (2016). ROBINS-I: a tool for assessing risk of bias in non-randomised studies of interventions. British Medical Journal, i4919. https://doi.org/10.1136/bmj.i4919

Sterne, J., Savović, J., Page, M., Elbers, R., Blencowe, N., Boutron, I., Cates, C., Cheng, H., Corbett, M., Eldridge, S. M., Emberson, J. R., Hernán, M. A., Hopewell, S., Hróbjartsson, A., Junqueira, D. R., Jüni, P., Kirkham, J. J., Lasserson, T., Li, T., ... Higgins, J. P. T. (2019). RoB 2: a revised tool for assessing risk of bias in randomised trials. British Medical Journal, 14898. https://doi.org/10.1136/bmj.14898

Sterne, J., Egger, M., \& Moher, D. (2008). Addressing reporting biases. Wiley.

Stufflebeam, D. (2001). The Metaevaluation Imperative. American Journal of Evaluation, 22(2), 183-209. https://doi.org/10.1177/109821400102200204

Suess, A., Pérez, I. R., Azarola, A. R., \& Cerdà, J. C. M. (2014). The right of access to health care for undocumented migrants: A revision of comparative analysis in the European context. European Journal of Public Health, 24(5), 712-720.

https://doi.org/10.1093/eurpub/cku036

Vaona, A., Banzi, R., Kwag, K., Rigon, G., Cereda, D., Pecoraro, V., Tramacere, I., \& Moja, L. (2018). E-learning for health professionals. Cochrane Database of Systematic 
medRxiv preprint doi: https://doi.org/10.1101/2020.06.26.20140566; this version posted June 26, 2020. The copyright holder for this preprint (which was not certified by peer review) is the author/funder, who has granted medRxiv a license to display the preprint in perpetuity. It is made available under a CC-BY-NC-ND 4.0 International license .

Reviews. https://doi.org/10.1002/14651858.CD011736.pub2

Wutoh, R., Boren, S., \& Balas, E. (2004). eLearning: A Review of Internet-based Continuing Medical Education. Journal of Continuing Education in the Health Professions, 24, 20 30. 